This item was submitted to Loughborough's Research Repository by the author.

Items in Figshare are protected by copyright, with all rights reserved, unless otherwise indicated.

\title{
Thermal properties and convective heat transfer of phase changing paraffin nanofluids
}

PLEASE CITE THE PUBLISHED VERSION

http://dx.doi.org/10.1016/j.ijthermalsci.2017.03.024

\section{PUBLISHER}

(C) Elsevier Masson SAS

\section{VERSION}

AM (Accepted Manuscript)

\section{PUBLISHER STATEMENT}

This work is made available according to the conditions of the Creative Commons Attribution-NonCommercialNoDerivatives 4.0 International (CC BY-NC-ND 4.0) licence. Full details of this licence are available at: https://creativecommons.org/licenses/by-nc-nd/4.0/

\section{LICENCE}

CC BY-NC-ND 4.0

\section{REPOSITORY RECORD}

Mikkola, Valtteri, Salla Puupponen, Kari Saari, Tapio Ala-Nissila, and Ari Seppala. 2019. "Thermal Properties and Convective Heat Transfer of Phase Changing Paraffin Nanofluids". figshare. https://hdl.handle.net/2134/25715. 


\title{
THERMAL PROPERTIES AND CONVECTIVE HEAT TRANSFER PERFORMANCE OF SOLID-LIQUID PHASE CHANGING PARAFFIN NANOFLUIDS
}

\author{
Valtteri Mikkola $^{1 *}$, Salla Puupponen ${ }^{1}$, Kari Saari $^{1}$, Tapio Ala-Nissila ${ }^{2,3}$ and Ari Seppälä ${ }^{1}$ \\ *Corresponding author \\ ${ }^{1}$ Aalto University School of Engineering, Department of Mechanical Engineering, Thermodynamics and \\ Combustion Technology, P.O. Box 14400, FI-00076 Aalto, Finland \\ ${ }^{2}$ Aalto University School of Science, Department of Applied Physics and COMP CoE, P.O. Box 11000, \\ FIN-00076 Aalto, Finland \\ ${ }^{3}$ Brown University, Department of Physics, P.O. Box 1843, Providence, RI 02912, USA \\ E-mail: valtteri.mikkola@aalto.fi
}

\section{ABSTRACT}

Fluids containing micro-sized solid-liquid phase changing particles have been proposed to be promising candidates as future heat transfer fluids. In addition, smaller nano-sized particles have been claimed to enhance the heat transfer performance of fluids even if the phase change is not exploited. We aim to combine these two concepts for the first time by studying fluids containing nano-sized phase changing particles. In this study, the convective heat transfer performance and the thermal properties of solidliquid phase changing paraffin nanofluids are experimentally examined. Three water-based paraffin nanofluids with particle mass fractions of $5-10 \%$ are prepared and measured with an annular tube heat exchanger. The heat transfer measurements cover both laminar and turbulent regimes with Reynolds numbers varying in the range of 700-11000. The measurements also include pressure losses in order to study the suitability of the fluids for practical forced convection applications. In addition, the fluids are characterized: latent heats, specific heats, viscosities, thermal conductivities, densities and particle size distributions are all determined experimentally. In agreement with previous studies, the nanofluids are found to exhibit Nusselt numbers clearly higher than water when compared on the basis of equal Reynolds numbers. However, the differences in Prandtl numbers are shown to explain these deviations in Nusselt numbers. Indeed, the well-known Gnielinski correlation is able to explain the results quite adequately and thus, significant anomalies in the convection heat transfer caused by neither the melting of the phase change material nor the presence of the nanoparticles are observed. However, the nanofluids have systematically slightly higher Nusselt numbers than the correlation would predict, but the deviations are within the accuracy of the correlation
(10\%). When compared by using equal pumping powers, the nanofluids exhibit heat transfer performance poorer than that of water. The positive impact of the latent heat is outweighed by the negative effects of the increased viscosity and decreased specific heat.

\section{INTRODUCTION}

In many heat transfer systems, the thermal energy is carried as sensible heat of a single-phase fluid. Since such systems are often operated with rather small temperature differences, the working fluids must be pumped at high volumetric flow rates resulting in remarkable pumping costs. Therefore, the thermal performance and the energy density of the working fluids is a major issue to be resolved.

Recently, the exploitation of phase change material (PCM) suspensions as heat transfer fluids has attracted wide attention, since the latent heat of the phase change could significantly improve the energy density of the fluid. In several studies, suspensions containing micro-sized PCM particles (typically $1-200 \mu \mathrm{m}$ ) have shown significant improvement in convective heat transfer performance [1-5]. However, the convection performance of such fluids containing nano-sized PCM particles has not been experimentally evaluated so far. The nanoscale might provide notable benefits over microscale, since suspensions containing solid nano-sized particles (nanofluids) or liquid droplets (nanoemulsions) have previously shown significantly enhanced convective heat transfer in several studies [6-12,19]. In addition, the smaller scale of particles may improve the stability of the fluids.

In this study, the presence of nano-sized particles and the latent heat of phase change are exploited simultaneously, hence combining these two keenly studied 
methods of enhancing heat transfer fluids. The aim is to experimentally examine the thermal properties and the convective heat transfer performance of water-based fluids containing nano-sized solid-liquid phase changing paraffin particles. Three such PCM nanofluid samples with different concentrations are prepared, characterized, measured and analyzed. The convective heat transfer performance is studied with an annular tube heat exchanger. The measurements cover both the laminar and turbulent regimes with Reynolds numbers varying in the range of 700-11000. In addition to the convective heat transfer, the analysis includes the change in the required pumping power due to the increased viscosity and friction factor caused by the nanoparticles. The nanofluids are also thoroughly characterized; latent heats, specific heats, viscosities, thermal conductivities, densities and particle size distributions are all determined experimentally.

\section{MATERIALS AND METHODS}

The paraffin nanofluids were prepared as follows. The solid paraffin wax (VWR Prolabo, predominantly straight chain hydrocarbons C20-C50) was first added to water and the mixture was heated to $70{ }^{\circ} \mathrm{C}$ in order to melt the paraffin. Then, the sodium dodecyl sulfate (SDS) surfactant was added to the solution $\left(\mathrm{m}_{\text {surfactant }} / \mathrm{m}_{\text {paraffin }}=\right.$ 1/3). After this, the fluid was stirred with ultrasonic processor (Hielscher 400UPS, $400 \mathrm{~W}$ ) for two hours (700 $\mathrm{g}$ sample at a time). Before the measurements, the fluids were filtered with paper filters (Whatman, pore size of 10 $\mu \mathrm{m})$. The mass of impermeable solids in the feed was negligible.

The latent heats, the phase change temperatures and the specific heats were determined using the Netzcsh DSC204FI Phoenix Differential Scanning Calorimeter (DSC). The uncertainty of the device was $1 \%$ for enthalpies and $0.5 \mathrm{~K}$ for onset temperatures (according to the manufacturer). All the DSC measurements were conducted using a $5 \mathrm{~K} / \mathrm{min}$ heating and cooling rate. In the latent heat and phase change temperature measurements, the sample was repeatedly heated and cooled in the temperature range of $5-80{ }^{\circ} \mathrm{C}$. The specific heats were measured using the temperature range of $10-90{ }^{\circ} \mathrm{C}$.

The particle size distributions were determined with Dynamic Light Scattering (DLS) method using the Malvern Zetasizer Nano ZS apparatus. The DLS measurements were conducted at temperatures of $15^{\circ} \mathrm{C}$ and $65^{\circ} \mathrm{C}$ in order to study the size distributions in both solid and liquid states of the particles. The fluid stabilities were studied by repeating the DLS measurements sequentially at least ten times, and by measuring the size distributions before and after the convective heat transfer measurements.
The viscosities were measured with two different viscometer types in order to ensure the measurement reliability and to compare the functionality of the different viscometers to measure samples containing solid-liquid phase changing nanoparticles. The two measurement devices were a Haake falling ball type $\mathrm{C}$ viscometer and the Brookfield DV3TLVCJ0 cone/plate rheometer. Based on the measurement repetition, the uncertainties of the devices were estimated to be $0.5 \%$ and $1.5 \%$, respectively. The temperature range in both viscosity measurements was $20-65{ }^{\circ} \mathrm{C}$, which was roughly equal to the temperature range of the convective heat transfer measurements. Since cooling of the samples may result in supercooling of liquid particles, the fluids were heated up during the viscosity measurements in order to ensure that the fluid states during the viscosity measurements would correspond to the states during the convective heat transfer experiments.

The thermal conductivities of the nanofluids were determined with the C-therm TCi-3-A thermal conductivity analyzer, based on modified transient source plane technique. The uncertainty of the device was $3 \%$ (reported by the manufacturer). The thermal conductivities were measured at room temperature. The densities were determined at temperatures of $20{ }^{\circ} \mathrm{C}, 45{ }^{\circ} \mathrm{C}$ and $65{ }^{\circ} \mathrm{C}$ using VWR hydrometers.

\section{CONVECTIVE HEAT TRANSFER MEASUREMENTS}

The convective heat transfer experiments were performed using an annular tube type counter flow heat exchanger, in which the nanofluid samples flowed in the inner tube and hot water flowed in the outer section (Fig. 1). The inner and outer tubes of the heat exchanger were $1.47 \mathrm{~m}$ long acid-resistant steel pipes with inner diameters of $6 \mathrm{~mm}$ and $13 \mathrm{~mm}$, respectively. The thickness of the inner pipe, which corresponds to the wall separating the two fluids, was $1 \mathrm{~mm}$. Before the heat exchanger, the nanofluid was cooled below $15{ }^{\circ} \mathrm{C}$ in order to ensure the complete solidification of the particles. The cooling was performed using a heat exchanger with cold water flowing in the external side. After this, the fluid was pre-heated to temperature of $20-25{ }^{\circ} \mathrm{C}$ using a heating bath in order to ensure that the fluid temperature in the measurement section would cover the whole melting temperature range of paraffin. The outlet temperatures of the heated nanofluid samples varied between $56^{\circ} \mathrm{C}$ and $70^{\circ} \mathrm{C}$, depending on the flow rates. The volumetric flow of nanofluid was varied in the range of $0.2-2.41 / \mathrm{min}$. The flow rates were controlled with pump frequency controllers. The hot water in the outer section entered into the heat exchanger at the temperature of $95-98{ }^{\circ} \mathrm{C}$ and cooled to $86-95{ }^{\circ} \mathrm{C}$, depending on the flow rate. The flow rate of hot water was varied in the range of $2.1-13.9 \mathrm{l} / \mathrm{min}$, depending on the 
flow rate of the nanofluid. The measurement conditions were altered from point to point in order to reach the temperatures required for the particle melting. Nevertheless, the measurement condition pattern was the same for all the fluids measured, thus allowing the fair comparability of the results. In order to prevent natural convection, the warming nanofluid was arranged to flow upwards in the vertically positioned heat exchanger. Consistently, the water flow on the external side was set to flow downwards.

The temperatures of the nanofluids were measured with two thermometers at the inlet point and another two at the outlet. Likewise, the temperature of the hot water in the external section was measured with two thermometers on each end of the tube. Before reaching the outlet thermocouples, the fluids in both sections were strangled in a narrow gap of $1 \mathrm{~mm}$ in diameter in order to ensure complete mixing of the fluid. With such an arrangement, cross-sectional temperature gradients were minimized, thus improving the quality of outlet temperature measurement. The apparatus for measuring pressure losses (Yokogawa DP Harp pressure transmitter) was connected to each end of the inner tube of the heat exchanger, with a distance of $1.68 \mathrm{~m}$. The velocities of nanofluid and water flows were measured with the Optiflux 4000 electromagnetic flow sensors. Based on the measurement repetition, the uncertainties were estimated to be approximately $1 \%$ for the heat transfer coefficients and $2 \%$ for the pumping powers.

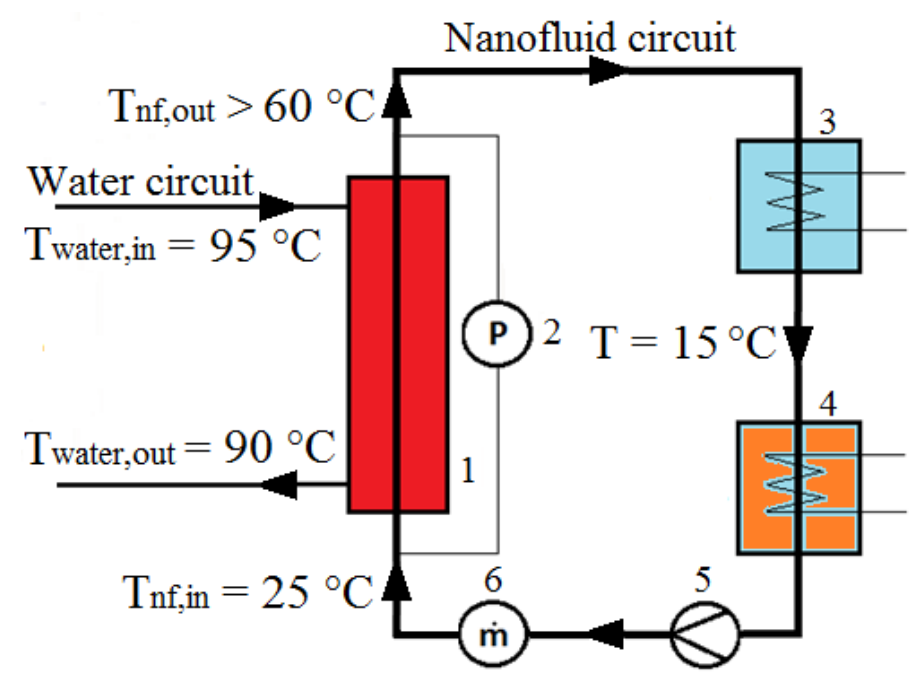

Fig 1. A schematic of the convection heat transfer measurement apparatus: an annular tube type heat exchanger (1), a pressure meter (2), a cooler (3), a preheater (4), a pump (5) and a flow meter (6).

\subsection{Determination of heat transfer coefficient}

Heat transfer coefficients were determined based on the measured inlet and outlet temperatures $T(\mathrm{~K})$, mass flows $\dot{m}(\mathrm{~kg} / \mathrm{s})$ and fluid properties. First, a logarithmic temperature difference is calculated using its definition.

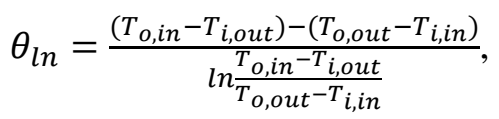

where the subscripts $i$ and $o$ refer to the inner and outer sections of the heat exchanger, respectively, and the subscripts in and out refer to inlet and outlet, respectively. The conductance $G(\mathrm{~W} / \mathrm{K})$ of the heat exchanger is defined as the ratio of the heat transfer power $\phi(\mathrm{W})$ and the logarithmic temperature difference $\theta_{\ln }(\mathrm{K})$ as

$G=\frac{\phi}{\theta_{l n}}=\frac{\dot{m} c_{p} \Delta T}{\theta_{l n}}$

where $c_{p}$ is the specific heat and $\Delta T$ is the temperature change of the fluid. The conductance per length can be also expressed as

$\frac{1}{G / L}=\frac{1}{\pi d_{i} h_{i}}+\frac{\ln \left(\frac{d_{o}}{d_{i}}\right)}{2 \pi \lambda_{\text {tube }}}+\frac{1}{\pi d_{o} h_{o}}$

where $d_{i}$ and $d_{o}(\mathrm{~m})$ are the inner and outer diameters of the tube, respectively, $h_{i}$ and $h_{o}\left(\mathrm{~W} / \mathrm{m}^{2} \mathrm{~K}\right)$ are the inner and outer heat transfer coefficients, respectively, and $\lambda$ is the thermal conductivity of the tube material (acid-resistant steel, $\lambda=15 \mathrm{~W} / \mathrm{mK}$ ). The heat transfer coefficient of nanofluid $h_{i}$ can be calculated after $h_{o}$ is determined using the well-known Dittus-Boelter correlation for turbulent flow.

$N u=0.023 \operatorname{Re}^{0.8} \operatorname{Pr}^{0.3}$,

Where $N u$ is the Nusselt number, $R e$ is the Reynolds number and $\mathrm{Pr}$ is the Prandtl number of the hot water flow. The Nusselt number was further corrected to correspond to the geometry of the duct between the annular tubes $\left(N u_{a n n}\right)$ using a method suggested by Petukhov and Roizen [13].

$N u_{\text {ann }}=0.86 N u_{D B}{\frac{d_{o}}{d_{i}}}^{0.16}$

\subsection{Determination of mean values}

Some fluid properties, such as viscosity, are strongly dependent on the temperature. In addition, the melting of the PCM causes the fluid properties to alter significantly inside the heat exchanger. Therefore, accurately predicted mean values that represent the convective heat transfer 
measurement conditions are required for the analysis of the results.

The mean temperatures and the mean fluid properties were determined using the following numerical method. The tube is divided in a thousand computation cells with equal lengths $L_{\text {cell }}$. The conductance $\mathrm{G}$ is assumed to be constant along the tube length. Starting from the entrance point of nanofluid with measured temperature values $T_{n f, \text { in }}$ and $T_{\text {water,out }}$, the heat transfer power of the cell $\left(\phi_{i}\right)$ can be calculated with equation

$\phi_{i}=\left(T_{\text {water }, i}-T_{n f, i}\right) \frac{G}{L_{\text {tot }}} L_{c e l l}$,

where $L_{t o t}$ is the length of the measurement section (1.47 $\mathrm{m})$. If the heat capacity flow (including the latent heat) is assumed to be constant, the temperature change of nanofluid in the cell $\left(\Delta T_{n f, i}\right)$ can be calculated as

$\Delta T_{n f, i}=\frac{\phi_{i}}{\phi_{T O T}}\left(T_{n f, \text { out }}-T_{n f, \text { in }}\right)$

Consistently, the temperature change of water in the cell $\left(\Delta T_{\text {water }, i}\right)$ is calculated as

$$
\Delta T_{\text {water }, i}=\frac{\phi_{i}}{\phi_{T O T}}\left(T_{\text {water }, \text { in }}-T_{\text {water }, \text { out }}\right)
$$

This algorithm is repeated to obtain the temperatures in all the cells. The calculated temperature values of the last cell are bound to be very close to the values measured ( $T_{n f \text { out }}$ and $T_{\text {water, in }}$ ), since the calculation method is based on the experimentally determined conductance and power. The mean temperatures and mean fluid properties used in the result analysis were obtained as averages of these thousand computational temperature points, which represent the longitudinal temperature profile inside the heat exchanger.

\section{RESULTS AND DISCUSSION}

The measured properties of the nanofluids are summarized in Table 1.

\subsection{Latent heat and specific heat}

A DSC measurement of a $10.0 \mathrm{w}-\%$ nanofluid is presented in Fig 2. The latent heats of the fluids were similar or slightly lower than those predicted based on the particle fractions and the latent heat of bulk paraffin $(159 \mathrm{~kJ} / \mathrm{kg})$. The latent heats of particles in the 5.0, 7.5 and $10.0 \mathrm{w}-\%$ paraffin nanofluids corresponded to $90 \%, 97 \%$ and $101 \%$ of the latent heat of bulk paraffin. In smaller length-scales, the ratio of the particle surface area and the volume becomes larger, and therefore the surface interactions have enhanced influence. The SDS surfactant used in the nanofluids studied has an impact on paraffin structure close to the particle surfaces, thus making changes in the latent heats and phase change temperatures possible [14]. However, only minor deterioration of the latent heat $(\leq 10 \%)$ was observed for these fluids, which is advantageous in terms of practical heat transfer applications. Similar behavior of the latent heat in smallscale systems has been reported in literature as well [15$16]$.

According to the DSC measurements, the melting of the particles in the fluids occurs at two almost separate periods: the first onset temperature is observed at $\sim 30{ }^{\circ} \mathrm{C}$, but the largest portion of the paraffin melts around $\sim 53{ }^{\circ} \mathrm{C}$ (Fig. 2). The melting temperatures were similar for all the PCM fluids studied. The melting occurs at rather broad temperature range, since the paraffin consists of several different hydrocarbons with the carbon numbers predominantly in the range of C20-C50. Such a large temperature range of melting can be considered both an advantage as well as a disadvantage in terms of practical applications: the energy density enhancement applies through a broad range of temperature, but on the other hand the associated sensible heat becomes large thus reducing the importance of the latent heat on total energy density. The solidification occurs in slightly lower temperatures of 22-39 ${ }^{\circ} \mathrm{C}$. Therefore, the supercooling degree of the paraffin particles is quite moderate $\left(\sim 20^{\circ} \mathrm{C}\right)$ which is eligible for practical forced convection applications. However, the supercooling degree may depend on the conditions, such as the cooling rate and the disturbance of the fluid.

The melting and solidification temperatures of PCM fluids correspond mostly to those of bulk paraffin. However, the bulk paraffin was found to melt at a slightly broader temperature range $\left(25-68{ }^{\circ} \mathrm{C}\right)$ than the PCM fluids $\left(30-59{ }^{\circ} \mathrm{C}\right)$. In addition, the solidification of the bulk initiates at slightly higher temperature of $51{ }^{\circ} \mathrm{C}$. The difference in the solidification onsets corresponds to the difference in the melting temperatures and thus, the supercooling degrees of the bulk and the PCM fluids are similar.

The relative specific heats in $20{ }^{\circ} \mathrm{C}$ and $65{ }^{\circ} \mathrm{C}$ are presented in Table 1. The specific heats between these temperatures could not be determined, since the latent heat of phase change disturbs the measurements. The reported specific heats are determined based on the cooling cycle measurements, since the temperature range of solidification is narrower than that of melting, thus causing no disturbance in the desired temperatures of $20^{\circ} \mathrm{C}$ and 65 ${ }^{\circ} \mathrm{C}$. The relative specific heats measured are same in both temperatures for all PCM fluids. Increasing paraffin concentration causes the specific heats to decrease, as expected. 
Table 1. The major material properties of the nanofluids at temperatures $20{ }^{\circ} \mathrm{C}$ and $65{ }^{\circ} \mathrm{C}$. Abbreviations: $\mathrm{T}$ - temperature, $\mathrm{D}_{\text {number }}$ - average particle size (diameter) base on the number distribution, $\mathrm{D}_{\text {volume }}-$ average particle size (diameter) based on the volume distribution, $\mathrm{PdI}$ - polydispersity index, $\Delta \mathrm{H}$ - latent heat of melting, $\mathrm{c}_{\mathrm{p}, \mathrm{nf}}$ and $\mathrm{c}_{\mathrm{p}, \mathrm{bf}}-$ specific heats of the nanofluid and water (respectively), $\rho_{\mathrm{nf}}$ and $\rho_{\mathrm{bf}}-$ densities of the nanofluid and water (respectively), $\lambda_{\mathrm{nf}}$ and $\lambda_{\mathrm{bf}}-$ thermal conductivities of the nanofluid and water (respectively).

\begin{tabular}{llllllllll}
\hline $\begin{array}{l}\text { Concentration } \\
(\mathrm{w}-\%)\end{array}$ & $\begin{array}{l}\mathrm{T} \\
\left({ }^{\circ} \mathrm{C}\right)\end{array}$ & $\begin{array}{l}\mathrm{D}_{\text {number }} \\
(\mathrm{nm})\end{array}$ & $\begin{array}{l}\mathrm{D}_{\text {volume }} \\
(\mathrm{nm})\end{array}$ & $\mathrm{Pdl}$ & $\begin{array}{l}\Delta \mathrm{H} \\
(\mathrm{kJ} / \mathrm{kg})\end{array}$ & $\mathrm{c}_{\mathrm{p}, \mathrm{nf}} / \mathrm{c}_{\mathrm{p}, \mathrm{bf}}$ & $\mu_{\mathrm{nf}} / \mu_{\mathrm{bf}}$ & $\rho_{\mathrm{nf}} / \rho_{\mathrm{bf}}$ & $\lambda_{\mathrm{nf}} / \lambda_{\mathrm{bf}}$ \\
\hline 5.0 & 20 & 167 & 482 & 0.23 & 7.1 & 0.98 & 1.40 & 0.997 & 0.93 \\
\hline 5.0 & 65 & 113 & 271 & 0.20 & 7.1 & 0.98 & 1.27 & 0.976 & - \\
\hline 7.5 & 20 & 142 & 864 & 0.40 & 12.1 & 0.96 & 1.65 & 0.995 & 0.90 \\
\hline 7.5 & 65 & 117 & 322 & 0.20 & 12.1 & 0.96 & 1.59 & 0.980 & - \\
\hline 10.0 & 20 & 203 & 799 & 0.38 & 16.5 & 0.92 & 2.36 & 0.995 & 0.86 \\
\hline 10.0 & 65 & 139 & 277 & 0.21 & 16.5 & 0.92 & 1.88 & 0.976 & - \\
\hline
\end{tabular}

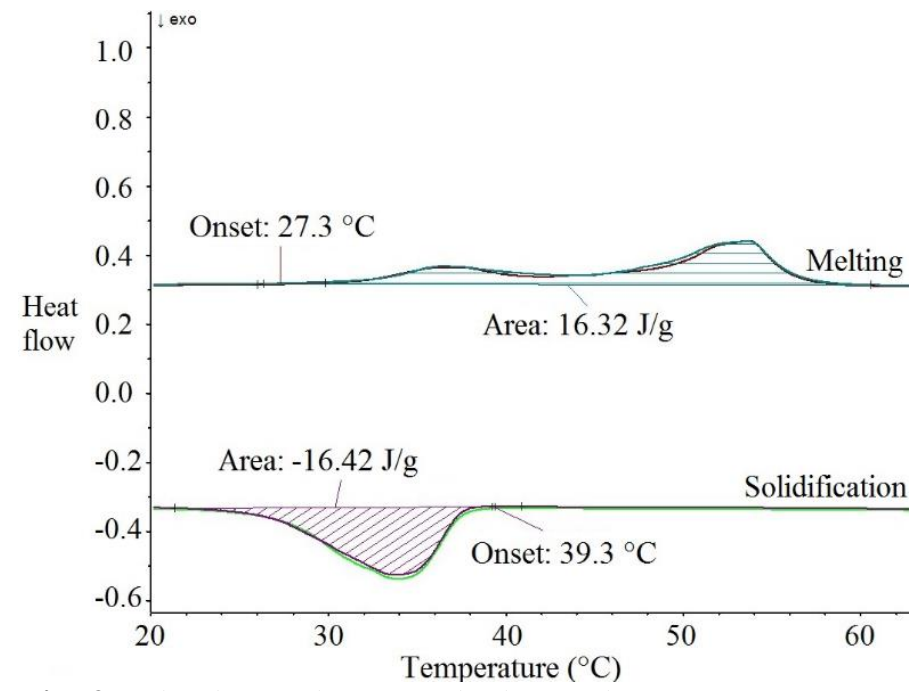

Fig 2. The latent heats and phase change temperatures determined with DSC.

\subsection{Particle size distribution}

The particle sizes and polydispersity indices measured with DLS are presented in Table 1 . The more accurate size distribution for the $5.0 \mathrm{w}-\%$ paraffin nanofluid is presented in Fig. 3, and the distributions of the other concentrations are similar. In solid state $\left(15^{\circ} \mathrm{C}\right)$, the particles appear to be larger than in liquid state $\left(65{ }^{\circ} \mathrm{C}\right)$. In addition, the distribution in liquid state is more uniform. Similar results were obtained also after 10 rounds of sequential heating and cooling of the samples. The size distributions of the fluids were also measured after the convective heat transfer measurements in order to ensure the dispersion stability during the experiments. The particle size distributions of all nanofluids remained unchanged during the heat transfer measurements.

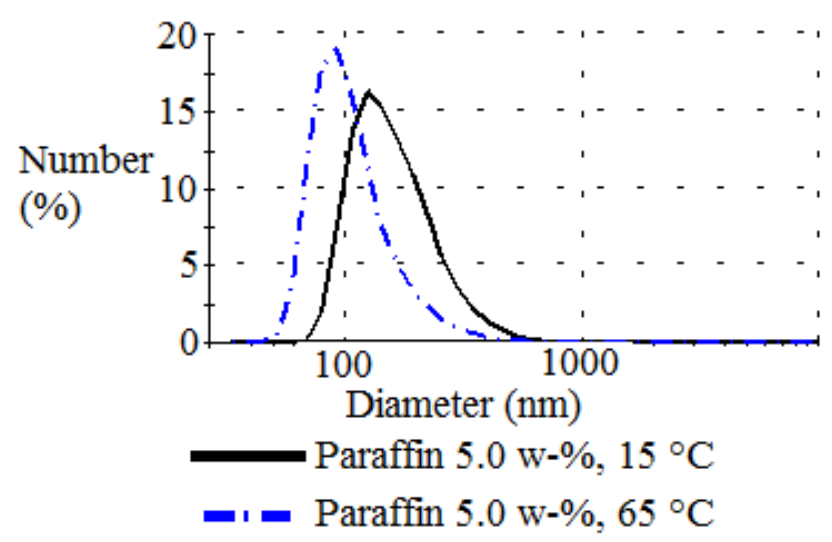

Fig 3. The particle size distribution determined with DLS.

\subsection{Viscosity}

The relative viscosities (the ratio between nanofluid and base fluid viscosities) measured at $20{ }^{\circ} \mathrm{C}$ and $65{ }^{\circ} \mathrm{C}$ are presented in Table 1. In addition, the relative viscosities are shown as a function of temperature in Fig 3. The state of the particles is observed to have a significant impact: the relative viscosities decrease quickly at the melting temperature of paraffin $\left(\sim 50{ }^{\circ} \mathrm{C}\right)$. However, in colder and warmer temperatures, in which the phase change does not occur, the relative viscosities are not dependent on the temperature. Similar behavior has earlier been reported in several publications for nanofluids and nanoemulsions [17-19,22]. Paraffin concentration has also a significant influence on viscosity, as expected. The relative viscosities of the nanofluids increase in a somewhat linear manner with increasing concentration.

The viscosities measured with the two different measurement devices (a Haake Type $\mathrm{C}$ falling ball viscometer and the Brookfield DV3TLVCJ0 cone/plate rotational rheometer) are mostly in agreement. Individual points show differences of up to $5.3 \%$, but the differences are uncorrelated and do not have any clear trend. The same 
temperature trends are observed with both measurement devices. However, the rotational viscometer was unable to measure the viscosity at temperature of $50{ }^{\circ} \mathrm{C}$, and yielded excessively high and inconsistent values instead. Therefore, these results are not presented here. The phenomenon can be attributed to the melting of the particles, which occurs the most intensively around $50{ }^{\circ} \mathrm{C}$ (Fig. 2).

The Newtonian behavior of the samples was studied using the rotational viscometer. All fluids behaved in Newtonian manner within the studied range of shear rate (500-1500 1/s) in the temperatures studied $\left(20{ }^{\circ} \mathrm{C}\right.$ and 60 $\left.{ }^{\circ} \mathrm{C}\right)$.

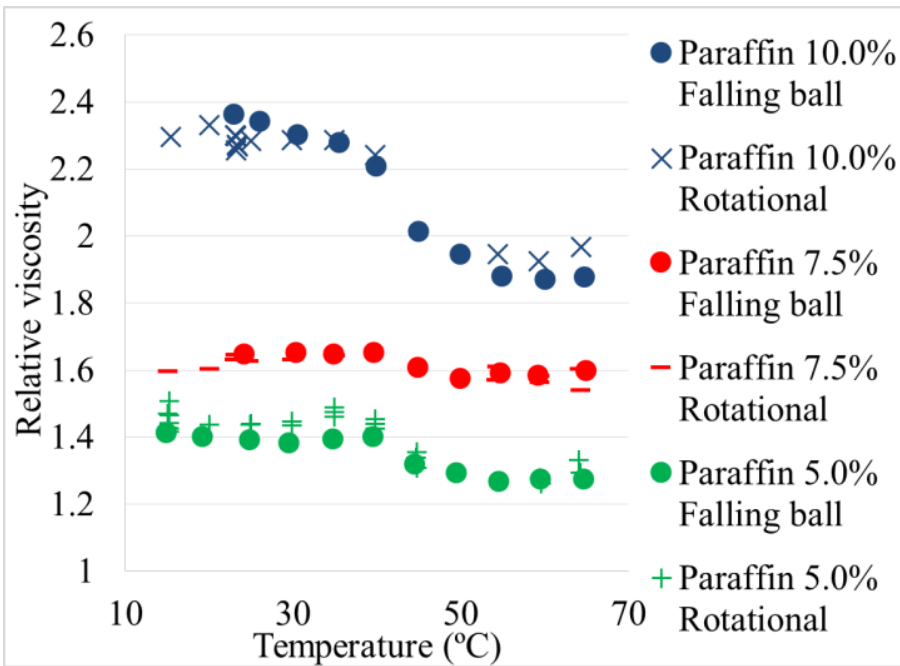

Fig 4. The relative viscosities of the nanofluids measured with the falling ball viscometer (circles) and the rotational viscometer.

\subsection{Density and thermal conductivity}

The relative densities and thermal conductivities of the nanofluids are presented in Table 1 . The density of liquid paraffin is lower than that of solid paraffin [20], and therefore the particle melting causes the nanofluid densities to decrease a few percents. This also means that the particle volume fractions of the nanofluids change slightly depending on the temperature. The thermal conductivities of the nanofluids decrease roughly in a linear manner with increasing paraffin concentration. Such a behavior was expected, since the thermal conductivity of solid paraffin at room temperature $(0.24 \mathrm{~W} / \mathrm{mK})$ is significantly lower than that of water $(0.60 \mathrm{~W} / \mathrm{mK})$ [20].

\subsection{Convective heat transfer}

The Nusselt numbers are presented as a function of the Reynolds numbers in Fig. 5. The PCM nanofluids reach higher $N u$ than water with an equal $R e$ in both laminar and turbulent regimes, and the deviation increases with increasing concentration. Similar behavior has also been widely reported in literature for nanofluids, nanoemulsions and PCM fluids [5-8,12,19,21-24,34]. However, this presentation method has been criticized in several recent publications, since it does not take the pumping power into account [21-26]. Therefore, the standard method is unable to assess the suitability of fluids for practical forced convection applications. In addition, the method disregards the influence of the Prandtl number and thus, it is also unable to state whether the performance of the fluids follow the conventional heat transfer correlations. Indeed, some recent publications have shown that the differences of $N u$ with equal $R e$ may be explained simply by considering $\operatorname{Pr}$ in the analysis [21,22,27]. Therefore, a direct comparison between experimental results and a standard correlation should be presented in order to assess whether or not the fluids exhibit anomalous convective heat transfer behavior. In this work, the well-known Gnielinski correlation [7] is used as a reference.

$$
N u_{G n i}=\frac{\left(\frac{f}{2}\right)(R e-1000) P r}{1+12.7\left(\frac{\mathrm{f}}{2}\right)^{1 / 2}\left(\operatorname{Pr}^{2 / 3}-1\right)}
$$

where

$f=(1.58 \ln R e-3.28)^{-2}$

The influence of the heat of melting is taken into account by defining an effective specific heat $c_{p, e f f}$, which is used in the determination of $\mathrm{Pr}$.

$c_{p, e f f}=c_{p}+\frac{\Delta H}{T_{\text {out }}-T_{\text {in }}}$

The experimental Nusselt numbers $\left(\mathrm{Nu}_{\exp }\right)$ are compared with the Gnielinski correlation $\left(\mathrm{Nu}_{\mathrm{Gni}}\right)$ in Fig. 6. The correlation seems to be able to explain the heat transfer behavior of the PCM nanofluids rather adequately and therefore, most of the differences observed based on equal $\operatorname{Re}$ (Fig. 5) can be explained by considering $\operatorname{Pr}$ (Fig. 6). The average deviations from the correlation are $0.8 \%$, $7.1 \%$ and $7.2 \%$ in the order of increasing concentration. The $7.5 \mathrm{w}-\%$ and $10.0 \mathrm{w}-\%$ fluids obtain rather systematically slightly higher Nusselt numbers, but the differences are within the uncertainty of the correlation, $10 \%$ [33]. These small deviations may indicate minor convection enhancement, but clear conclusions of such a small differences cannot be drawn due to the limits of the accuracy of the correlation and the experiments. Consequently, it can be concluded that significant anomalies in the convection caused by neither the melting of the PCM nor the presence of the nanoparticles are observed. 
The density difference between solid and liquid paraffin is rather small and thus, the melting does not result in significant mixing of the thermal boundary layer, such as encountered with evaporation. In addition, the SDS surfactant restricts the movement of the particles and prevents the density drop of melting from causing significant cross-sectional motion that would be beneficial in terms of convection. The particles are thus forced to maintain a relatively even distribution throughout the fluid in spite of the local density differences between the particles and the base fluid.

The results indicate that heat transfer coefficients of relatively low concentrated PCM nanofluids can be assessed with reasonable accuracy using the conventional correlations. Naturally, more unexpected results might be obtained with yet higher concentrations. The particle fractions studied herein (5-10 w-\%) are rather high for nanofluids, but even higher concentrations are often studied in the class of micro PCM fluids $(\sim 30 \%)[2,5,28]$.

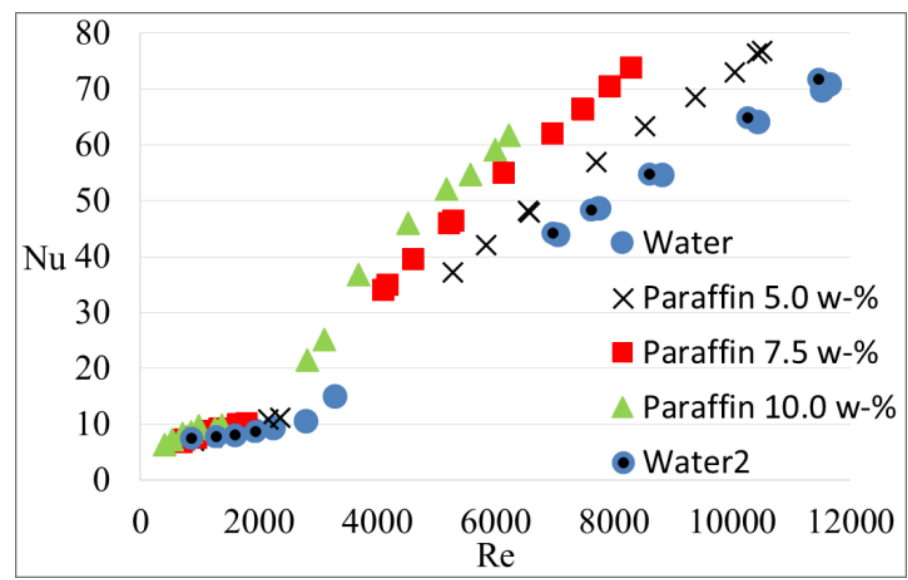

Fig 5. The Nusselt numbers as a function of Reynolds numbers. The water reference was measured before (Water) and after the paraffin experiments (Water2).

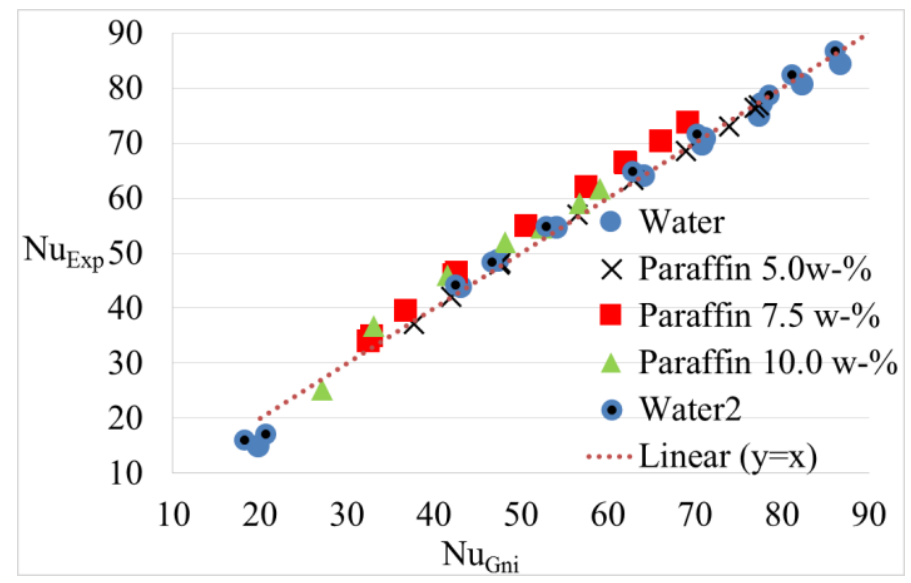

Fig 6. The convective heat transfer compared to the Gnielinski correlation (transition and turbulent regimes, $R e$ > 3000).

\subsection{Friction factors and pressure losses}

The Darcy friction factors are presented in Fig 7. The experimental values of all fluids measured follow the trends estimated for laminar and turbulent flow. However, the values seem to shift slightly towards the left with increasing concentration, as observed also by Wang et al. [2]. This indicates, that the paraffin nanofluids exhibit viscous behavior that would be expected from fluids with slightly lower viscosities. With fixed flow rates, the higher viscosities of the more concentrated fluids result in lower Reynolds numbers, but the pressure losses of the nanofluids do not increase correspondingly. Instead, the pressure losses remain somewhat unchanged with a fixed flow rate (Fig. 8). Almost all the data falls within the uncertainties of $1 \%$ for both pressure losses and velocities. Therefore, the fluids studied herein do not exhibit penalties in pressure losses, which is advantageous in terms of performance in practical applications. Previously, pressure loss penalties of various magnitudes have been reported for both nanofluids and PCM fluids [3,5,12,21,22,29]. In addition, even decreased pressure losses have been reported for PCM fluids in some cases, but that phenomenon can be mostly attributed to turbulence suppression i.e. flow laminarization [5,30-31].

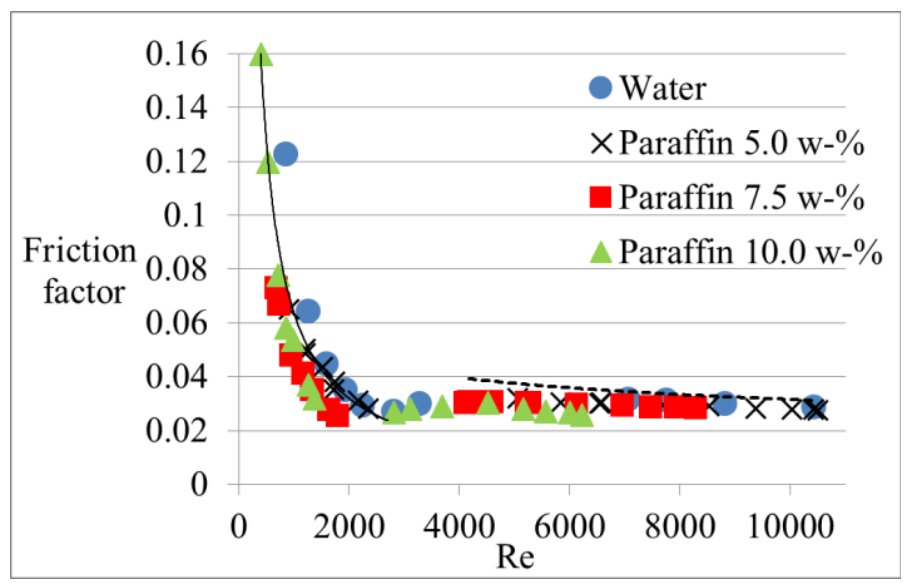

Figure 7. The Darcy friction factors. The solid and dashed lines represent the analytical solution for laminar pipe flow (64/Re) and the Blasius law (correlation) [32] for turbulent flow, respectively. 


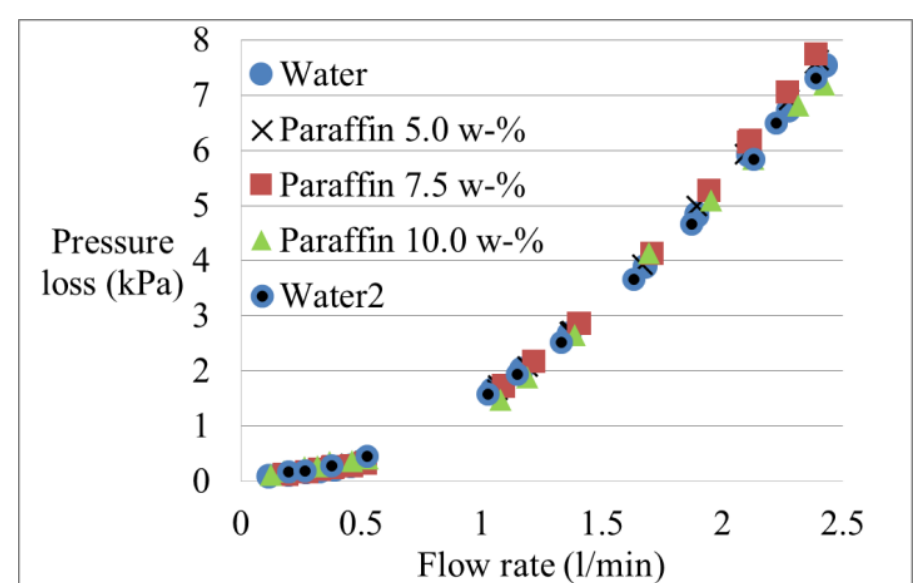

Figure 8. The pressure losses.

\subsection{Phase change}

In a constantly circulating flow loop, sufficient inlet and outlet temperatures do not confirm unambiguously that the phase change occurs. For example, slow phase change kinetics could result in incomplete melting of the PCM in high flow velocities. Therefore, the complete melting of the PCM fluids was confirmed also based on the measured heat transfer power differences between the nanofluid and water sides of the heat exchanger. In Figure 9, the latent heats calculated in this manner are compared with the latent heats based on DSC measurements. The values include notably high uncertainty of tens of percents, since the errors of almost each value measured have a contribution here. In particular, a $1 \%$ error in the specific heat could result in an error of $\sim 20 \%$, since the power of the latent heat is relatively small compared to power of the sensible heat. In the laminar regime, also the heat loss through the outer tube has a notable impact, thus further reducing the accuracy. Nevertheless, Fig. 10 shows that the latent heats observed correspond roughly to the latent heats measured with DSC, thus verifying that the melting did occur inside the heat exchanger.

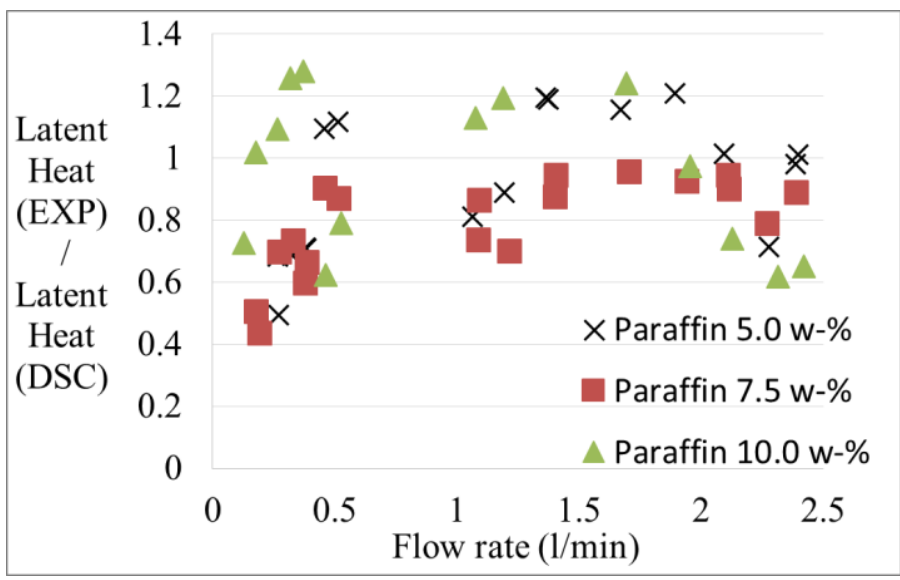

Fig 9. The phase change observed in the convective heat transfer measurements $(\operatorname{Re}=700-11000)$.

\subsection{Convective heat transfer efficiency}

Figures 10 and 11 describe the effective heat transfer performance of the fluids: the heat transfer powers are presented as a function of pumping power. This comparison yields insight into the suitability of the fluids for practical forced convection applications. On this basis, the addition of nanoparticles seems to deteriorate the fluid performance, despite the exploitation of the latent heat of the melting particles. All three nanofluids show lower performance than water, and the performance decreases with increasing concentration. This can be interpreted as the beneficial impact of the melting being outweighed by the negative effects caused by the increased viscosity and decreased specific heat. The fluids studied herein require rather a large temperature change $\left(\sim 30^{\circ} \mathrm{C}\right)$ for complete melting of the particles. In addition, the fractions of PCM $(\leq 10.0 \mathrm{w}-\%)$ are rather small when compared to those of some micro-scale phase change slurries measured in earlier studies (up to $\sim 30 \%$ ) [2,5,28]. Therefore, most of the energy is still carried as sensible heat, and the latent heat has a relatively small contribution $(\leq 12.3 \%)$ to the total energy density. Consequently, a narrower temperature range of melting would be more desirable for PCM heat transfer fluids. This could be obtained for instance with use of pure alkanes as PCM instead of paraffin consisting of mixture of alkanes. However, pure alkanes are significantly more expensive than paraffin. In addition, such fluids might also have higher supercooling degrees, which should be addressed in order to obtain feasibility for practical forced convection applications.

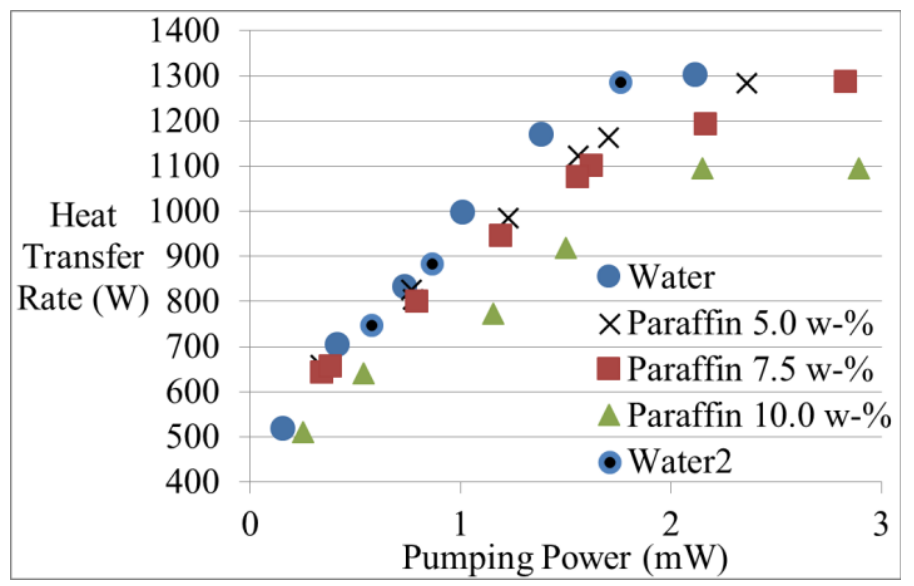

Fig 10. The effective heat transfer performance in the laminar regime 


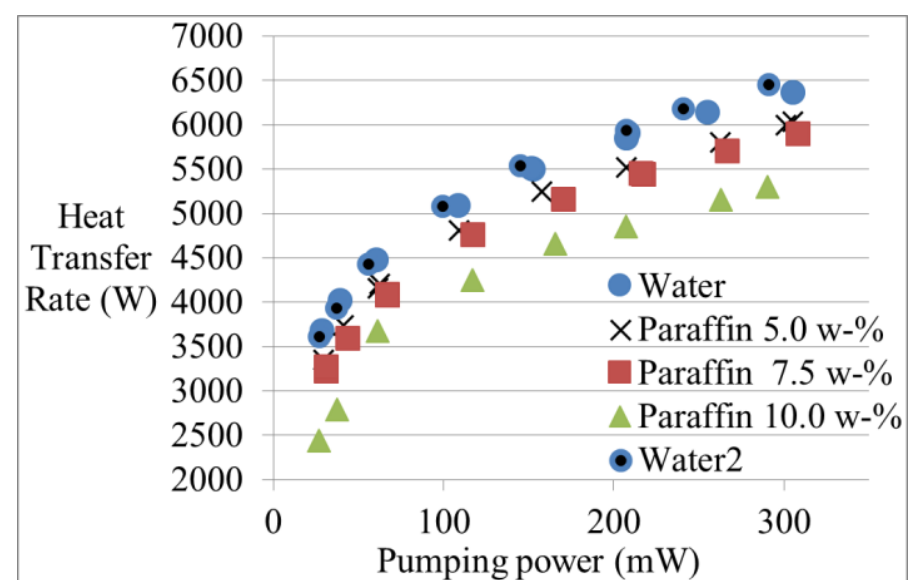

Fig 11. The effective heat transfer performance in the turbulent regime

\section{CONCLUSIONS}

The convective heat transfer performance of nanofluids containing solid-liquid phase changing paraffin particles was experimentally studied. Three water-based paraffin nanofluids with different concentrations (5.0, 7.5 and 10.0 $\mathrm{w}-\%)$ were prepared and measured with an annular tube heat exchanger. The thermal properties and the structure of the fluids were also thoroughly characterized: latent heats, specific heats, viscosities, thermal conductivities, densities and particle size distributions were all determined experimentally.

Significant anomalies in the convection heat transfer caused by neither the melting of the PCM nor the presence of the nanoparticles were observed. This indicates that the convective heat transfer of relatively low concentrated solid-liquid phase changing nanofluids can be predicted with reasonable accuracy using the conventional correlations. However, higher concentrations than those studied herein $(\leq 10 \mathrm{w}-\%)$ may result in less predictable behavior.

When compared on the basis of equal pumping powers, the nanofluids showed poorer performance than water. This can be interpreted as follows: the positive impact of the latent heat of melting is outweighed by the negative effects of the higher viscosity and lower specific heat. Therefore, the fluids studied herein do not seem suitable for practical forced convection applications. More promising results might be obtained for example by using PCMs with narrower melting temperature ranges.

The nanofluids and water showed similar pressure losses with equal velocities and thus, no notable pressure loss penalties due to the nanoparticles were observed. Indeed, the friction behavior of the nanofluids did not fully correspond to the predicted behavior for fluids as viscous, but the nanofluids exhibited slightly lower friction factors instead.
The addition of the paraffin particles caused the density, the specific heat and the thermal conductivity to decrease, and the viscosity to increase, as expected. The melting of the particles was observed to decrease the relative viscosity. This indicates that liquid droplets cause less resistance on the flow than solid particles. In temperature ranges in which the melting does not occur, the relative viscosities were somewhat independent on the temperature.

\section{ACKNOWLEDGEMENTS}

The research was funded by the Aalto Energy Efficiency Research Programme (EXPECTS-project), Efficient Energy Use (EFEU) research program coordinated by CLEEN Ltd. with funding from the Finnish Funding Agency for Technology and Innovation, Tekes, and the Academy of Finland through its COMP CoE grants 251748 and 284621 (T. A-N.).

\section{REFERENCES}

[1]Inaba, H., Kim, M. and Horibe, A., Melting Heat Transfer Characteristics of Microencapsulated Phase Change Material Slurries with Plural Microcapsules Having Different Diameters, ASME Journal of Heat Transfer, Vol. 126, pp. 558-565, 2004

[2]Wang, X., Niu, J., Li, Y., Wang, X., Chen, B., Zeng, R., Song, Q and Zhang, Y., Flow and Heat Transfer Behaviors of Phase Change Material Slurries in a Horizontal Circular Tube, International Journal of Heat and Mass Transfer, Vol. 5, pp. 2480-2491, 2007

[3]Cho, K., Choi, M., Experimental Study on the Application of Paraffin Slurry to High Density Electronic Package Cooling, Heat and Mass Transfer, Vol. 36, pp. 29-36, 2000

[4]Goel, M., Roy, SK. And Sengupta, S., Laminar Forced Convection Heat Transfer in Microencapsulated Phase Change Material Suspensions, International Journal of Heat an Mass Transfer, Vol. 37, pp. 593-604, 1994

[5]Yamagishi, Y., Takeuchi, H., Pyatenko, AT. and Kayukawa, N., Characteristics of Microencapsulated PCM Slurry as a Heat-Transfer Fluid, AIChE Journal, Vol. 45, pp. 696-707, 1999

[6]Michaelides, E. E., Nanofluidics: Thermodynamic and transport properties, Springer, 2014. ISBN: 978-3-319-05620-3

[7]Kakac, S., Yener, Y. and Pramuanjaroenkij, A., Convective heat transfer (Third edition), CRC Press, Taylor\&Francis Group, 2014. ISBN: 978-1-4665-8344-3

[8]Sarkar, J., A critical review on convective heat transfer correlations of nanofluids, Renewable and sustainable energy reviews, Vol. 15, pp.3271-3277, 2011

[9]Anoop, K. B., Sundararajan, T. and Das, S.K., Effect of particle size on the convective heat transfer in nanofluid in the developing region, International journal of heat and mass transfer, Vol. 52, pp. 2189-2195, 2009

[10]Chen, H., Yang, W., He, Y., Ding, Y., Zhang, L., Tan, C., Lapkin, A.A. and Bavykin, D.V., Heat transfer and flow behaviour of aqueous suspensions of titanate nanotubes (nanofluids), Powder Technology, Vol. 183, pp. 63-72, 2008

[11]Gupta, M., Arora, N., Kumar, R., Kumar, S. and Dilbaghi, N., A comprehensive review of experimental investigations of forced convective heat transfer characteristics for various nanofluids, International journal of mechanical and materials engineering, 2014 [12]Meriläinen, A., Seppälä, A., Saari, K., Seitsonen, J., Ruokolainen, J., Puisto, S., Rostedt, N. and Ala-Nissila, T., Influence of particle size 
and shape on turbulent heat transfer characteristics and pressure losses in water-based nanofluids, International journal of heat and mass transfer, Vol. 61, pp. 439-448, 2013

[13]Cengel, Y. A., Heat transfer - A practical approach, 2. Edition, McGraw-Hill, pp. 444, 2003 ISBN: 0-07-115150-8

[14]Günther, E., Huang, L., Mehling, H. and Dötsch, C., Subcooling in PCM emulsions - Part 2: Interpretation in Terms of Nucleation, Thermochimica Acta, Vol. 522, pp. 199-204. 2011

[15]Huang, J. Wang, T., Zhu, P. and Xiao, J., Preparation, Characterization, and Thermal Properties of the Microencapsulation of a Hydrated Salt as Phase Change Energy Storage Materials, Thermochimica Acta, Vol. 557, pp. 1-6, 2013

[16]Puupponen, S. Seppälä, A., Vartia, O., Saari, K. and Ala-Nissila, T., Preparation of Paraffin and Fatty Acid Phase Changing Nanoemulsions for Heat Transfer, ThermoChimica Acta, Vol. 601, pp. 33-38, 2015

[17]Esfe, M. and Saedodin, S., An experimental investigation and new correlation of viscosity of $\mathrm{ZnO}-\mathrm{EG}$ nanofluid at various temperatures and different solid volume fractions, Experimental thermal and fluid science, Vol. 55, pp. 1-5, 2014

[18]Chen, H., Ding, Y., He, Y. and Tan, C., Rheological behavior of ethylene glycol based titania nanofluids, Chemical physics letters, Vol. 444, pp. 333-337, 2007

[19]Saarinen, S. Puupponen, S., Meriläinen, A., Joneidi, A., Seppälä, A., Saari, K. and Ala-Nissila, T., Turbulent heat transfer characteristics in a circular tube and thermal properties of n-decane-in-water nanoemulsion fluids and micelles-in-water fluids, International journal of heat and mass transfer, Vol. 81, pp. 246-251, 2015

[20]Kotiaho, V., Lampinen, M. and Seppälä, A., Termodynamiikan ja lämmönsiirto-opin taulukoita, Aalto University, Department of energy engineering, 2004. ISBN 951-22-7557-0

[21]Mikkola, V., Puupponen, S., Granbohm, H., Saari, K., Ala-Nissila, T. and Seppälä, A., Convective Heat Transfer Performance of Polystyrene, $\mathrm{SiO}_{2}, \mathrm{Al}_{2} \mathrm{O}_{3}$ and Micelle Nanofluids, $12^{\text {th }}$ International Conference on Heat Transfer, Fluid Mechanics and Thermodynamics (HEFAT12) Proceedings (Accepted Manuscript), 2016

[22]Mikkola, V., Impact of concentration, particle size and thermal conductivity on effective convective heat transfer performance of nanofluids (Master's thesis), Aalto University School of Engineering, Department of Energy Technology, 2015

[23]Haghighi, E. B., Single phase convective heat transfer with nanofluids: An experimental approach (Doctoral thesis), KTH industrial engineering and management, Department of energy technology, Division of applied thermodynamics and refrigeration, 2015. ISBN: 978-91-7595-414-1

[24]Wu, Z., Wang, L. and Sunden, B., Pressure drop and convective heat transfer of water and nanofluids in a double-pipe helical heat exchanger, Applied thermal engineering, Vol. 60, pp. 266-274, 2013

[25]Yu, W., France, D.M., Timofeeva, E.V., Singh, D. and Routbort, J.L., Thermophysical property-related comparison criteria for nanofluid heat transfer enhancement in turbulent flow, Applied physics letters, Vol. 96, 2010

[26]Yu, W., Comparative review of turbulent heat transfer of nanofluids, International journal of heat and mass transfer, Vol. $55 \mathrm{pp}$. 5380-5396, 2012

[27]Buschmann, M. H., Nanofluid Heat Transfer In Laminar Pipe Flow with Twisted Tape, Heat Transfer Engineering, DOI: 10.1080/01457632.2016.1177381, 2016

[28]Yamagishi, Y., Sugeno, T., Ishige, T., Takeuchi, H. and Pyatenko, A.T., An Evaluation of Microencapsulated PCM for Use in Cold Energy Transportation Medium, Energy Conversion Engineering Conference IECEC 96, Proceedings of the $31^{\text {st }}$ Intersociety, Vol. 3, pp. 2077-2083, 1996
[29]Abbasian Arani, A. A. and Amani, J., Experimental Investigation on heat transfer performance and pressure drop of $\mathrm{TiO}_{2}$-water nanofluid, Experimental Thermal and Fluid Science, Vol. 44, pp. 520-533, 2013

[30]Alvarado, J. L., Marsh, C., Sohn, C., Phetteplace, G., Newell, T., Thermal Performance of Microencapsulated Phase Change Material Slurry in Turbulent Flow under Constant Heat Flux, International Journal of Heat and Mass Transfer, Vol. 50, pp. 1938-1952, 2007

[31]Kostic, M., On Turbulent Drag and Heat Transfer Reduction Phenomena and Laminar Heat Transfer Enhancement in Non-Circular Duct Flow of Certain Non-Newtonian Fluids, International Journal of Heat and Mass transfer, Vol. 37, pp. 133-147, 1994

[32]White, F. M., Viscous fluid flow (third edition), McGraw-Hill, 2006. ISBN: 007-124493-X

[33]Incropera, F. P. and De Witt, D. P., Fundamentals of Heat and Mass Transfer (third edition), John Wiley \& Sons, Inc., 1990, ISBN: 0-47151729-1

[34]Choi, M. and Cho, K., Effect of the Aspect Ratio of Rectangular Channels on the Heat Transfer and Hydrodynamics of Paraffin Slurry Flow, International Journal of Heat and Mass Transfer, Vol. 44, pp. 5561,2001 